\title{
BENTUK INTERFERENSI SINTAKSIS BAHASA INDONESIA DALAM BERBAHASA ARAB
}

\author{
Muhammad Natsir, Ana Rahmawati \\ UNISNU Jepara \\ Email: bilfanasir@gmail.com, anarahmawati@unisnu.ac.id
}

\begin{abstract}
Interference often occurs in foreign language learners because of the grammatical dominance of the first language in the learner when reducing meaning to the target language or second language. Interference can be identified by two approaches, namely; contrastive analysis and language error analysis. The purpose of the results of the studies and analyzes that have been done, to find out some of the structure of Indonesian language as the first language to enter and dominate in the structure of the Arabic language. This is evident in several mistakes made by learners of language in Arabic in various written languages (insha ') or verbal (mukhadatsah), and these errors are found in some patterns and sentence structures in expressing a meaning (ta'bir) or meaning expressed by learners in the language they use. There are several elements of Indonesian language syntax (L1) which dominate in the pattern of Arabic language structure in various written or oral languages used by Arabic learners (L2), and first language dominance is evident and found in some errors in the second language, including; 1) $\mathrm{P}+\mathrm{O}+\mathrm{S}$ sentence pattern with transitive verbs. 2) $\mathrm{P}+\mathrm{S}+\mathrm{O}$ sentence pattern with transitive verbs. 3) $\mathrm{D}+\mathrm{M}$ sentence pattern using task words (Jar). 4) Subject by using an + Fi'il mudhorik. 5) D + $M$ pattern sentence with variation Kaana wa akhowatuha. 6) Use of adjectives (tarkib bayani). 7) Use of sentences. 8) Use of links between words. 9) Use of numbers in sentences.
\end{abstract}

Keywords: language interference, syntax, Arabic, qualitative descriptive method.

\begin{abstract}
Abstrak
Interferensi sering terjadi pada pembelajar bahasa asing karena adanya dominasi gramatikal bahasa pertama pada diri pembelajar ketika mereduksi makna ke dalam bahasa target atau bahasa kedua. Interferensi dapat diidentifikasi dengan dua pendekatan, yaitu; analisis kontrastif dan analisis kesalahan berbahasa. Tujuan dari hasil studi dan analisis yang telah dilakukan, untuk mengetahui beberapa struktur bahasa Indonesia sebagai bahasa pertama yang masuk dan mendominasi dalam struktur bahasa arab. Hal ini tampak jelas pada beberapa kesalahan yang dilakukan oleh pembelajar bahasa dalam berbahasa Arab dalam ragam bahasa tulis (insya') ataupun lisan (mukhadatsah), dan kesalahan tersebut ditemukan pada beberapa pola dan struktur kalimat dalam mengungkapkan sebuah makna (ta'bir) atau makna yang diungkapkan oleh pembelajar dengan bahasa yang digunakannya.Terdapat beberapa unsur sintaksis bahasa Indonesia (L1) yang mendominasi dalam pola struktur bahasa Arab pada ragam bahasa tulis ataupun lisan yang digunakan oleh pembelajar bahasa Arab (L2), dan dominasi bahasa pertama tampak jelas dan ditemukan pada beberapa kesalahan pada bahasa kedua, diantaranya yaitu; 1) Pola kalimat $\mathrm{P}+\mathrm{O}+\mathrm{S}$ dengan kata kerja transitif. 2) Pola kalimat $\mathrm{P}+\mathrm{S}+\mathrm{O}$ dengan kata kerja transitif. 3) Pola kalimat D + M dengan menggunakan kata tugas (Jar). 4) Subjek dengan
\end{abstract}

Vol. 1 No. 2 / October 2018

IJAZ ARABI homepage: http://ejournal.uin-malang.ac.id/index.php/ijazarabi 
menggunakan an + Fi'il mudhorik. 5) Kalimat pola D + M dengan variasi Kaana wa akhowatuha. 6) Penggunaan kata sifat (tarkib bayani). 7) Penggunaan sifat berbentuk kalimat. 8) Penggunaan penghubung antar kata. 9) Penggunaan bilangan dalam kalimat.

Kata kunci: interferensi bahasa, sintaksis, bahasa Arab, metode deskriptif kualitatif.

\section{A. PENDAHULUAN}

Kualitas pembelajaran bahasa Arab di lingkungan mahasiswa saat ini cenderung menurun, hal ini dikarenakan timbulnya berbagai hambatan yang dihadapi mahasiswa. (Suja'i, 2008). Salah satu hambatan yang menyebabkan menurunnya minat belajar mahasiswa ialah ketika mereka kesulitan memahami materi bahasa asing dalam tataran mendengar, membaca, menulis maupun praktik berbicara.

Dalam pembelajaran bilingual maupun multilingual selalu muncul masalah kebahasaan. Diantaranya masalahnya yang berhubungan dengan Interferensi dan integrasi bahasa (Malibari, 1976). Hal ini disebabkan karena dua faktor; pertama, banyaknya perbedaan dan persamaan antara bahasa keseharian merekadengan bahasa Arab yang sedang dipelajari. Kedua, seberapa besar potensi mahasiswa dapat memberi pengaruh terhadap proses pembelajaran bahasa Arab.

Sering kali ditemukan kesalahan-kesalahan yang dilakukan mahasiswa ketika mereka mempelajari bahasa Arab, yaitu berupa penyimpangan aturan atau struktur kalimat bahasa Arab. Hal ini dikarenakan aturan kedua bahasa yang berbeda antara satu dengan yang lain, yaitu bahasa mereka seharai-hari dengan bahasa asing yang mereka pelajari.

Sengaja ataupun tidak sengaja seringkali terjadi kesalahan ketika mahasiswa menggunakan bahasa tertentu karena kebiasaan menggunakan dua bahasa secara bergantian dalam rutinitas sehari-hari. Berikut contoh bentuk Interferensi sintaksis sederhana yang sering dilakukan oleh mahasiswa ketika proses pembelajaran bahasa Arab berlangsung di kelas: الكتاب ذلك جديد dan yang benar dalam struktur bahasa Arab seharusnya ذلك الكتاب جديد.

Interferensi bahasa biasa terjadi disemua komponen bahasa baik dari sisi fonologi, leksikal, semantic, morfologi dan sintaksis (Rahardi, 2010). Karena permasalahan yang dialami mahasiswa dalam belajar bahasa Arab, maka dalam kesempatan kali ini peneliti lebih memfokuskan penelitian dari komponen sintaksisnya. Hal tersebut berdasarkan pada hasil observasi peneliti bahwa Interferensi bahasa yang seringkali terjadi pada mahasiswa UNISNU Jepara dan mahasiswa IPMAFA Pati adalah sesuatu yang berhubungan dengan sintaksis.

Kajian-kajian yang terkait dengan Interferensi sudah banyak ditemukan. Namun, kajian yang terkait dengan Interferensi sintaksis dalam ranah bahasa Arab masih terbilang sedikit. Oleh karena itu, perlu dilakukan penelitian yang terkait dengan kajian tentang interferensi sintaksis bahasa Indonesia dalam berbahasa Arab dan fokus peneliti pada materi Muhadatsah maupun Insya'. Karena bentuk kesalahan mahasiswa dalam Muhadatsah maupun Insya' tidak dapat dipandang sebagai kesalahan yang lumrah. Namun,hal itu harus dicari solusinya agar kesalahan-kesalahan terjadi dapat diminimalisir dengan materi dan strategi belajar bahasa Arab yang tepat, sehingga upaya tersebut dapat 
mengurangi bentuk-bentuk Interferensi bahasa dalam keterampilan berbahasa Arab.

\section{B. TINJAUAN PUSTAKA}

\section{Interferensi Bahasa}

Menurut Tarigan dan Lilis interferensi sintaksis ialah bentuk kekacauan pemakaian bahasa yang diakibatkan karena adanya kontak dalam bentuk penerapan kaidah bahasa pertama dalam penggunaan bahasa kedua. Adanya kontak tersebut menimbulkan pengaruh di dalam penerapan antara sistem bahasa yang pertama dan dalam penerapan sistem bahasa kedua, begitu pula sebaliknya.

Penyimpangan kaidah masing-masing bahasa. Semisal, anak berbahasa Indonesia, maka secara tidak sadar anak tersebut akan menggunakan sistem bahasa Indonesia ketika mereka berbicara berbahasa Arab. Adanya saling mempengaruhi ini biasa terjadi pada setiap unsur bahasa yaitu unsur sintaksis dan morfologi.

Unsur bahasa yang saling mempengaruhi antara bahasa pertama dan kedua disebut dengan istilah transfer. Terjadinya positive transfer apabila bahasa pertama tidak mempengaruhi kaidah bahasa kedua. Sedangkan negative transfer (interferensi) terjadi apabila bahasa pertama mempengaruhi kaidah bahasa kedua yang mengakibatkan kejanggalan makna. Dengan demikian interferensi dapat didefinisikan dengan penggunaan kaidah bahasa pertama dalam mengaplikasikan bahasa kedua.

Interferensi dapat disimpulkan sebagai bentuk kekeliruan yang disebabkan terbawanya kebiasaan dialek dalam bahasa pertama ke dialek bahasa kedua. Bahasa Indonesia sebagai bahasa ibu yang dikuasai penuturnya akan memberi pengaruh yang besar ketika penutur belajar bahasa kedua. Secara sosiolinguistik masyarakat Indonesia tidak hanya berbahasa satu, namun bisa menggunakan dua bahasa yakni bahasa ibu (bahasa daerah) dan bahasa Indonesia (bahasa nasional). Penggunaan dua bahasa atau lebih tersebut disebut kedwibahasaan. Apabila terjadi disslokasi dalam struktur bahasa pertama dalam bahasa kedua disebut sebagai gangguan atau interferensi.

Gejala interferensi menurut sifatnya dibagi menjadi tiga bagian: 1) interferensi yang sifatnya aktif yang berupa kebiasaan-kebiasaan pada bahasa kedua, 2) interferensi yang sifatnya pasif tidak digunakan dalam bentuk bahasa kedua dikarenakan tidak adanya pola bentuk tersebut dalam bahasa pertama, 3) interferensi yang sifatnya variasional, dalam bentuk kebiasaan bahasa yang beragam dalam bahasa pertama yang terbawa dalam bahasa kedua. Interferensinya dalam bentuk cara mengucapkan ataupun membentuk kata maupun kalimat.

\section{Sintaksis}

Sintaksis berasal dari bahasa Yunani yakni sun yang artinya dengan dan kata "tattein" yang berarti menempatkan bersama dengan kata-kata menjadi sebuah kata ataupun kalimat. Sintaksis merupakan cabang dari linguistik yang berhubungan dengan susunan kata dalam kalimat. Sintaksis berhubungan dengan struktur antar kata ataupun struktur eksternal. Dengan batasan tersebut berarti kalimat merupakan satuan terbesar dalam sintaksis dan seluruh bahasa mempunyai kaidah sintaksis masing-masing yangmana tidak dapat diterapkan begitu saja pada bahasa lain.

Sintaksis merupakan kajian tentang kaidah penggabungan kata menjadi satuan frasa atau kalimat. Hal tersebut menggambarkan bahwa satuan sintaksis ialah frasa ataupun kalimat yang didalamnya terdapat kata. Sedangkan menurut Stryker dalam Muliono, 
sintaksis merupakan kajian tentang pola-pola kombinasi kata untun pembentukan kalimat.

Dari berbagai pendapat pakar di atas dapat disimpulkan bahwa sintaksis ialah bagian dari tata bahasa yang memberi bentuk ragam penggabungan kata menjadi kalimat yang tersusun struktural yaitu dari frasa, klausa dan kalimat, dengan susunan kata tang terstruktur tersebut memiliki makna yang benar dan baik.

\section{METODE PENELITIAN}

Metode penelitian dalam penelitian ini menggunakan metode deskriptif kualitatif. Yaitu dengan mengumpulkan data yang bersifat kualitatif dan menggunakan analisis kualitatif dalam pemaparan data, analisis data serta dalam proses pengambilan kesimpulan. Menurut Sugiyono metode deskriptif ialah suatu metode yang digunakan untuk menggambarkan ataupun menganalisis suatu hasil penelitian namun tidak digunakan dalam membuat kesimpulan yang lebih luas. Metode kualitatif yang dimaksudkan ialah dimana peneliti mengamati fenomena yang ada di lapangan yang menggambarkan serta menjabarkan temuan di lapangan, yang kemudian memanfaatkan wawancara agar dapat ditelaah segala yang terjadi di lapangan (Sugiyono, 2010).

Penelitian deskriptif memiliki tujuan untuk menggambarkan, dan meringkaskan segala kondisi, situasi atau berbagai variabel yang timbul di masyarakat yang dijadikan objek penelitian. Sehingga menarik ke permukaan sebagai salah satu ciri atau gambaran tentang kondisi, situasi ataupun variabel tertentu. Dengan demikian peneliti akan berusaha menggambarkan, meringkaskan berbagai kondisi atau variabel yang ada pada saat penelitian dilakukan.

Adapun sumber data primer di peroleh dari hasil observasi dan interview atau wawancara dengan informan sebanyak -banyaknya tentang segala aspek yang berhubungan dengan permasalahan yang diteliti. penulis menggunakan informan untuk memperoleh data yang dibutuhkan. Teknik pengumpulanInforman ini menggunakanteknik purposif, yakni teknik pengambilan informan secara sengaja, peneliti menentukan sendiri informan yang akan diambil karena ada pertimbangan- pertimbangan tertentu. Adapun pemilihan informan ini dengan pertimbangan bahwa orang yang dipilih tersebut dapat memberikan informasi melalui wawancara dengan jelas dan akurat sesuai dengan tujuan dan kebutuhan atas permasalahan yang diteliti tersebut.Yang menjadi informan dalam penelitian ini ialah: mahasiswa UNISNU Prodi Pendidikan Agama Islam dan mahasiswa IPMAFA Prodi Bahasa Arab. Sedangkan data sekunder diambil dari dokumen maupun studi putaka.

Data yang diperoleh tersebut dianalisis secara bersamaan dengan proses pengumpulan data, analisis data berdasarkan data dari hasil wawancara yang kemudian dicatat dan dikumpulkan sehingga menjadi catatan lapangan.

\section{HASIL DAN PEMBAHASAN} Indonesia

Beberapa Kesalahan Ungkapan Bahasa Arab Sebab Interferensi Sintaksis Bahasa

a) Pola kalimat $\mathrm{S}+\mathrm{P}+\mathrm{O}$ dan $\mathrm{S}+\mathrm{P}+\mathrm{O}$ dengan kata kerja transitif (muta'addi bi harfi jar) analisis kontrastif diantara kedua bahasa sebagaimana pada tabel berikut: 


\begin{tabular}{|c|c|c|}
\hline $\begin{array}{c}\text { Ungkapan bahasa arab } \\
\text { yang mengalami } \\
\text { Interferensi }\end{array}$ & $\begin{array}{c}\text { Struktur kalimat } \\
\text { bahasa Indonesia yang } \\
\text { benar }\end{array}$ & $\begin{array}{l}\text { Struktur kalimat bahasa } \\
\text { arab yang benar }\end{array}$ \\
\hline نستطيع حلتلك المشكلات & $\begin{array}{l}\text { Kita mampu enyelesaikan } \\
\text { permasalahan tersebut } \\
\text { dengan baik }\end{array}$ & المشتكلات جيد عن حل تلك \\
\hline النبي أمرنا لتكريم الضيف & $\begin{array}{l}\text { Nabi memerintahkan } \\
\text { kepada kita untuk } \\
\text { menghormati tamu }\end{array}$ & أمرنا النبي بتكريم الضيف \\
\hline 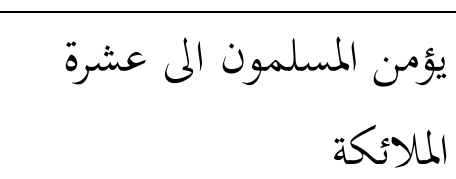 & $\begin{array}{l}\text { Kaum muslim beriman } \\
\text { kepada sepuluh malaikat }\end{array}$ & 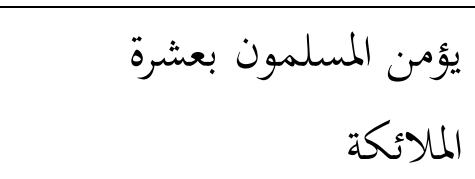 \\
\hline
\end{tabular}

b) Pola kalimat $\mathrm{P}+\mathrm{S}+\mathrm{O}$ dengan kata kerja transitif (muta'addi tanpa huruf jar)

\begin{tabular}{|c|c|c|}
\hline $\begin{array}{c}\text { Ungkapan bahasa arab } \\
\text { yang mengalami } \\
\text { Interferensi }\end{array}$ & $\begin{array}{l}\text { Struktur kalimat bahasa } \\
\text { Indonesia yang benar }\end{array}$ & $\begin{array}{l}\text { Struktur kalimat bahasa } \\
\text { arab yang benar }\end{array}$ \\
\hline يجب ان نفهم الى ضرورة & $\begin{array}{l}\text { Kita harus memahami } \\
\text { kepentingan masyarakat }\end{array}$ & يجب ان نفهم ضرورة المجتمع \\
\hline البحتمع & & \\
\hline يجب يعلم المسلم بواجبانه & $\begin{array}{l}\text { Seorang muslim harus } \\
\text { mengetahui kewajbannya }\end{array}$ & يجب ان يعلم المسلم واجباته \\
\hline
\end{tabular}

c) Pola kalimat $\mathrm{D}+\mathrm{M}$ dengan menggunakan kata tugas (huruf Jar)

\begin{tabular}{|c|c|c|}
\hline $\begin{array}{l}\text { Ungkapan bahasa arab } \\
\text { yang mengalami } \\
\text { Interferensi }\end{array}$ & $\begin{array}{l}\text { Struktur kalimat bahasa } \\
\text { Indonesia yang benar }\end{array}$ & $\begin{array}{l}\text { Struktur kalimat bahasa } \\
\text { arab yang benar }\end{array}$ \\
\hline الله لديه تسعة وتسعون اسما & Allah memiliki 99 nama & الله تسعة وتسعون اسما \\
\hline المسلمون لديه الكتاب & $\begin{array}{l}\text { Orang-orang muslim } \\
\text { memiliki kitab al-Qur'an } \\
\text { yang mulia }\end{array}$ & الكريميكمين الكتاب القرآن \\
\hline
\end{tabular}

d) Subjek dengan menggunakan variasi an + Fi'il Mudhori'

\begin{tabular}{|c|c|c|}
\hline $\begin{array}{c}\text { Ungkapan bahasa arab } \\
\text { yang mengalami } \\
\text { Interferensi }\end{array}$ & $\begin{array}{l}\text { Struktur kalimat bahasa } \\
\text { Indonesia yang benar }\end{array}$ & $\begin{array}{l}\text { Struktur kalimat bahasa } \\
\text { arab yang benar }\end{array}$ \\
\hline يجب على المسلمين يجب & $\begin{array}{l}\text { Umat islam harus mencintai } \\
\text { Tuhan dan RasulNya }\end{array}$ & يجب على المسلمين ان يجبوا \\
\hline & & \\
\hline
\end{tabular}

Vol. 1 No. 2 / October 2018

IJAZ ARABI homepage: http://ejournal.uin-malang.ac.id/index.php/ijazarabi 


\begin{aligned} \hline يلزم علينا ان نفهم شريعة & $\begin{array}{l}\text { Kita harus memahami } \\ \text { syari'at Islam }\end{array} \\$ الإسلزم علينا نفهم شريعة & \end{aligned}

e) Kalimat pola D + M dengan variasi Kaana wa akhowatuha

\begin{tabular}{|c|c|c|}
\hline $\begin{array}{c}\text { Ungkapan bahasa arab } \\
\text { yang mengalami } \\
\text { Interferensi }\end{array}$ & $\begin{array}{c}\text { Struktur kalimat } \\
\text { bahasa Indonesia yang } \\
\text { benar }\end{array}$ & $\begin{array}{c}\text { Struktur kalimat bahasa } \\
\text { arab yang benar }\end{array}$ \\
\hline الحضا الإسلامية تصبح & $\begin{array}{l}\text { Peradaban islam adalah } \\
\text { peradaban yang maju } \\
\text { sepanjang masa }\end{array}$ & كتطورة على مر العصلارة الإسلامية حضارة \\
\hline الآن هو يصير ناجح في & $\begin{array}{l}\text { Sekarang dia menjadi } \\
\text { orang sukses dalam } \\
\text { perdagangan/bisnis }\end{array}$ & الآن يصير ناجحا في التجارة \\
\hline تئ التدريسئة يصبح مشكلة & $\begin{array}{l}\text { Peemasalahan tersebut } \\
\text { menjadi problem dalam } \\
\text { pembelajaran }\end{array}$ & أصبحت تلك المسائل مشكلة في \\
\hline
\end{tabular}

f) Penggunaan kata sifat

\begin{tabular}{|c|c|c|}
\hline $\begin{array}{c}\text { Ungkapan bahasa arab } \\
\text { yang mengalami } \\
\text { Interferensi }\end{array}$ & $\begin{array}{c}\text { Struktur kalimat } \\
\text { bahasa Indonesia yang } \\
\text { benar }\end{array}$ & $\begin{array}{c}\text { Struktur kalimat bahasa } \\
\text { arab yang benar }\end{array}$ \\
\hline كريم الله أنزل القرآن في رمضان & $\begin{array}{l}\text { Allah menurunkan al- } \\
\text { Qur'an bulan Romadlon } \\
\text { yang mulia }\end{array}$ & أنزل الله القرآن في رمضان الكييم \\
\hline نذهيب الى "مدينة جبارا " & $\begin{array}{l}\text { Kita pergi ke kota jepara } \\
\text { yang indah bersama } \\
\text { rombongan }\end{array}$ & ل لم الى "مدينة جبارا " \\
\hline
\end{tabular}

g) Penggunaan sifat berbentuk kalimat

\begin{tabular}{|c|c|c|}
\hline $\begin{array}{l}\text { Ungkapan bahasa arab } \\
\text { yang mengalami } \\
\text { Interferensi }\end{array}$ & $\begin{array}{l}\text { Struktur kalimat bahasa } \\
\text { Indonesia yang benar }\end{array}$ & $\begin{array}{c}\text { Struktur kalimat } \\
\text { bahasa arab yang } \\
\text { benar }\end{array}$ \\
\hline شهر رجب هو الشهر العظيم & $\begin{array}{l}\text { Bulan Rajab adalah bulan yang } \\
\text { agung bagi umat Islam, bulan } \\
\text { yang di dalamnya terjadi } \\
\text { peristiwa Isra' dan mi'roj } \\
\text { Rasululloh saw }\end{array}$ & لمن شر عظيم \\
\hline
\end{tabular}

Vol. 1 No. 2 / October 2018

IJAZ ARABI homepage: http://ejournal.uin-malang.ac.id/index.php/ijazarabi 


\begin{tabular}{|c|c|c|}
\hline صلى الإسراء والمعراج لرسول الله عليه وسلم & & والمعراجلرسول الله صلى عليه وسلم \\
\hline كان ليلة القدر ونزول القرآن & $\begin{array}{l}\text { Romadlon bulan mulia yang di } \\
\text { dalamnya ada malam lailatul } \\
\text { Qodar turunnya al-Qur'an }\end{array}$ & ليلة القدر ونزول شهر عظيم فيه \\
\hline
\end{tabular}

h) Penggunaan kata penghubung

\begin{tabular}{|c|c|c|}
\hline $\begin{array}{c}\text { Ungkapan bahasa arab } \\
\text { yang mengalami } \\
\text { Interferensi }\end{array}$ & $\begin{array}{l}\text { Struktur kalimat bahasa } \\
\text { Indonesia yang benar }\end{array}$ & $\begin{array}{c}\text { Struktur kalimat } \\
\text { bahasa arab yang } \\
\text { benar }\end{array}$ \\
\hline يجبب على كل مسلم أقيموا & $\begin{array}{l}\text { Setiap muslim harus } \\
\text { melaksanakan sholat, } \\
\text { menunaikan zakata, } \\
\text { berpuasa di bulan Romadlon } \\
\text { dan melaksanakan haji } \\
\text { ketika sudah mampu } \\
\text { melaksanakannya. }\end{array}$ & اليجب على كل مسلم إقامة \\
\hline توضأ، اداء الصلاة، تناول احد من النوم، ثم & $\begin{array}{l}\text { Ahmad bangun tidur, lalu } \\
\text { berwudhu, melaksanakan } \\
\text { sholat, sarapan kemudian } \\
\text { berangkat ke sekolah }\end{array}$ & فتوضأ فاداء الصلاة فتناول الند من النوم \\
\hline الفطور ثم ذهب الى المدرسة & & المدرسة تم ذهب الى \\
\hline
\end{tabular}

i) Penggunaan susunan bilangan

\begin{tabular}{|c|c|c|}
\hline $\begin{array}{c}\text { Ungkapan bahasa arab } \\
\text { yang mengalami } \\
\text { Interferensi }\end{array}$ & $\begin{array}{c}\text { Struktur kalimat } \\
\text { bahasa Indonesia } \\
\text { yang benar }\end{array}$ & $\begin{array}{l}\text { Struktur kalimat bahasa } \\
\text { arab yang benar }\end{array}$ \\
\hline هناك عشرون وخمسة من الأنبياء & $\begin{array}{l}\text { Ada } 25 \text { nabi dan Rasul } \\
\text { yangdiimani oleh setiap } \\
\text { muslim }\end{array}$ & كانت خمسة وعشرون نبيا \\
\hline كان اثنا عشر الشهر في داخل & $\begin{array}{l}\text { Ada } 12 \text { bulan dalam } \\
\text { setahun bagi perjalanan } \\
\text { kehidupan manusia }\end{array}$ & كان كرور اثنا عشر شهرا في السنة \\
\hline
\end{tabular}

Terdapat beberapa unsur sintaksis bahasa Indonesia (L1) yang mendominasi dalam pola struktur bahasa Arab pada ragam bahasa tulis ataupun lisan yang digunakan oleh pembelajar bahasa Arab (L2), dan dominasi bahasa pertama tampak jelas dan ditemukan pada beberapa kesalahan pada bahasa kedua, diantaranya yaitu; 1) Pola kalimat $\mathrm{P}+\mathrm{O}+\mathrm{S}$ dengan kata kerja transitif. 2) Pola kalimat $\mathrm{P}+\mathrm{S}+\mathrm{O}$ dengan kata kerja transitif. 3) Pola

Vol. 1 No. 2 / October 2018

IJAZ ARABI homepage: http://ejournal.uin-malang.ac.id/index.php/ijazarabi 
kalimat $\mathrm{D}+\mathrm{M}$ dengan menggunakan kata tugas (Jar). 4) Subjek dengan menggunakan an + Fi'il mudhori'. 5) Kalimat pola D + M dengan variasi Kaana wa akhowatuha. 6) Penggunaan kata sifat (tarkib bayani). 7) Penggunaan sifat berbentuk kalimat. 8) Penggunaan penghubung antar kata. 9) Penggunaan bilangan dalam kalimat.

\section{E. KESIMPULAN}

Interfernesi terjadi pada ranah unsur-unsur kebahasaan yang meliputi; phonologi, morfologi, sintaksis serta semantik. Dari hasil studi dan analisis yang telah dilakukan, terdapat beberapa struktur bahasa Indonesia sebagai bahasa pertama yang masuk dan mendominasi dalam struktur bahasa Arab. Hal ini tampak jelas pada beberapa kesalahan yang dilakukan oleh pembelajar bahasa dalam berbahasa Arab dalam ragam bahasa tulis (insya') ataupun lisan (muhadatsah), dan kesalahan tersebut ditemukan pada beberapa pola dan struktur kalimat dalam mengungkapakan sebuah makna (ta'bir) atau makna yang diungkapkan oleh pembelajar dengan bahasa yang digunakannya.

\section{DAFTAR PUSTAKA}

Budiarty, Any. Interferensi Bahasa Indonesia Ke Dalam Bahasa Inggris Pada Abstrak Jurnal Ilmiah. (Jurnal: Bahasa dan Seni, Vol. 41, No. 1, Februari 2013.

Henry, Guntur Tarigan. 1984. Pengajaran Sintaksis. Bandung: Angkasa.

Lekova, B. Language Interference And Methods Of Its Overcoming In Foreign Language Teaching, (Trakia Journal Of sciences, Vol. 8, Suppl. 3, pp 320-324, 2010).

Malibari, A Akrom dkk. Pedoman Pengajaran Bahasa Arab Pada Perguruan Tinggi Agama/UIN, (Jakarta: Depag RI, 1976).

Moeliono, Anton M. Tata Bahasa Buku Bahasa Indonesia. (Jakarta: Balai Pustaka, 2000).

Ramlan, M. 1981. Ilmu Bahasa IIndonesia: Sintaksis. Yogyakarta: CV Karyono.

Rahardi, R. Kunjana. Kajian Sosiolinguistik. (Bogor: Ghalia Indonesia, 2010).

Sugiyono. 2010. Metode Penelitian Pendidikan, Kualitatif, Kuantitatif, dan Riset \& Development. Bandung: ALFABETA.

Suja'i. Inovasi Pembelajaran Bahasa Arab. (Semarang: Walisongo Press, 2008).

Tarigan dan Sulistianingsih. 1996. Analisis Kesalahan Berbahasa. Jakarta: Departemen Pendidikan dan Kebudayaan Dirjen Pendidikan. 